\title{
THE GIG IS UP: WHO DOES GIG ECONOMY ACTUALLY BENEFIT?
}

Luka Bulian*

\author{
University of Zagreb, Faculty of Mechanical Engineering and Naval Architecture \\ Zagreb, Croatia
}

DOI: 10.7906/indecs.19.1.9

Received: 10 January 2021.

Regular article

Accepted: 30 March 2021.

\begin{abstract}
This article takes on the task of exploring gig economy in its various forms and definitions, starting from its economic origins as a way to reduce transaction costs and overheads in firms making use of modern technology, and working up to some of its social consequences, such as the transforming of employees in just-in-time resources, fragmenting their labour and eroding their ability to organize and unionize in order to better defend their rights. Focussing on the influence platforms have on their users, be it in the role of workers or customers, it questions their far-reaching impacts on society and economy in terms of their positive, neutral or negative consequences for workers, as most of the literature agrees on the heavily skewed positive consequences for businesses. In order to make sense of existing research made on "giggers" this article tries to provide a scope of the gig economy using, which has been difficult to achieve as numerous researchers, institutions, and even states, define gig economy in different ways, with their data varying depending on definitions, dates, and methodological approaches. Finally, the article explores three distinct "selling points" of gig economy, namely: the possibility to generate (not always) steady income, the flexibility it offers to its users, and its consequences on workers' social and emotional state, putting into question their benefits for workers, for the profit of platforms and businesses.
\end{abstract}

\section{KEY WORDS}

gig economy, platform economy, work force, precarity

\section{CLASSIFICATION}

JEL: J21, J22, J23, J28, J46 


\section{IN SEARCH OF DEFINITIONS}

Crowd working, freelancing, gig economy, sharing economy, on-demand economy, platform economy, those are just a few names by which this new business/employment/economy model goes by $[1,2]$ depending which authors, institutions, and disciplines one refers to the most.

Although it's given name may vary, precarious work by any other name would still smell as insecure, and the rules of the game would still be much the same for all the (not)employees and (not)employers playing it.

By definition, gig work is "short term, task based, insecure, and precarious" [1; p.755], and, although it has been around long before our hyperconnected contemporary society, is now mostly dependent on digital/online platforms, such as Airtasker, Fiverr, Uber and many more [1]. Such digital platforms, also referred to as "marketplaces" or "transaction platforms" "are characterized by their open business models that inherently rely on independent participants to co-create value" [3; p.319]. Although the authors [3] offer a taxonomy of 6 different types of platforms, depending on their participants, values, transaction and goods types, and revenue models, platforms do share a common denominator - they provide a marketplace where labour demand and supply can meet via apps or internet browsers, in order to link workers of any background and age with clients or corporations of any country or scale, for a fee.

While Churchill and Lyn [1], in their research, found that the most common tasks gig workers performed were driving, for men $(27,8 \%)$, and photography and design related tasks for women $(24,1 \%)$, following the broad eligibility gig workers enjoy, it does not come as a surprise that they can be found operating in a myriad other occupations. The same authors [1] found gig workers performing tasks such as caring, cleaning, designing software or graphics, delivering, driving, maintaining, repairing, gardening, building, and numerous others, while Friedman [4; p.172] finds that "they work for low wages as personal care attendants, dog walkers, and day laborers for landscapers, and for high wages as managers of IT installations, accountants, editors, lawyers, and business consultants".

As various authors note $[1,5,6]$, gigs, although mediated via apps and platforms, do not necessarily have to be worked online to qualify as such. Consequently, gigs could be either physical or digital tasks performed locally or remotely, depending on whether or not the workers need to be physically present $[1,6]$, and referred to as "work on demand" or "crowd work" depending on their nature.

De Stefano, for instance, defines crowdwork as "completing a series of tasks through online platforms" [5; pp.471-472], while comparing work on demand to a more standard view of work, if ever more fragmented, "such as transport, cleaning, and running errands..." in which giggers apply for tasks through apps owned by firms that exert at least a minimum of control regarding the quality of service and selection of workforce [5; pp.471-472].

Although one would expect the firms who own the apps to be considered employers, or at least intermediaries between workers and employers, such a relation never comes to fruition in the gig economy. As Urzì Brancati et al. put it "the object of each mediation is not a job in the traditional sense, but a single task or service" [7; p.4], so the worker never actually becomes an employee, as he "is not paid a wage or salary, does not have an implicit or explicit contract for a continuing relationship, and does not have a predictable work schedule or predictable earnings when working." [8; p.357] but is instead considered self-employed.

As self-employed individuals, giggers find themselves playing under a completely different set of rules compared to "standard" employees with unsatisfactory levels of job security and planning [9], which are, only sometimes and in some measure counterbalanced by the level of 
flexibility they could possibly achieve, and, while popular culture and mass media tend to promote such a mode of "employment" as a "be your own boss" culture which allows them a level of flexibility unattainable to the population working "from 9 to 5", being a gigger often comes with more challenges than benefits, as it will be further discussed in the Benefits and beneficiaries chapter of the article.

In the next sections of the article we will turn to examining the individuals comprising the gig workforce as well the economic processes that accelerated its rise, and the social consequences that come with it.

\section{WHO CONSTITUTES THE GIG WORKFORCE?}

Measuring gig economy has been a challenge to researchers worldwide, which is not surprising as it is difficult to measure something that's yet to be defined. Are giggers unemployed, employed (and if so, under what kind of contract?) but with a side job, independent contractors, or all of the above? De Stefano [5] notes that a vast majority of giggers are usually classified as independent contractors but, as Manyika et al. [9] put it, there is not a single criterion that can be used to classify independent workers. Focussing on three factors, namely, a high degree of autonomy, payment by task, assignment or sales, and shortterm relationships between the worker and the client [9], the authors argue that there's a, more or less clear difference between independent workers and other types of employment. Excluding (sub)contractors or temporary workers like "permatemps who have long-term contracts and are expected to work regular hours" [9; p.21], franchise owners and other representatives of fissured work, they attempt to measure the scope of gig economy somewhat more conservatively compared to, e.g. Gallup [10] who include (independent) contractors, on-call workers, online platform workers, and temporary workers. Depending on the definition of the population of gig workers, and confining results to all-encompassing research provided by market research agencies such as Manyika et al. and Gallup [9, 10], the gig workforce ranges from 10 to 36 percent of the working age population, depending on country, year and usage of gigs (as primary or supplementary income). It should be noted here, that, as Manyika et al. and Gallup [9, 10] integrate different independent workers in their analyses, and do so in different years, this article will be confined to data provided by Manyika et al. [9] who, although is surely outdated by now (published in 2016), provides data for both the EU and the U.S.A., unlike Gallup [10] who only examines the U.S.A. albeit a few years later.

The McKinsey report [9] estimates the number of gig workers from 84 to 130 million people in both the U.S.A. and five European countries examined (France, Germany, Spain, Sweden and the U.K.), raising the estimate to 60-93 million when generalizing data to EU-15 - which would account for 18-28\% of the European working-age population.

Exploring the structure of these independent workers, McKinsey report results [9] show that gig work is the primary source of income for $46 \%$ American and $42 \%$ of European independent workers, although it should be noted and taken as a mitigating circumstance that the majority of independent workers engage in gig activity by choice rather than out of necessity, with "only" $28 \%$ of Americans and $32 \%$ of Europeans gigging because they need to.

Depending on the reason of gig work engagement, the McKinsey report differentiates between four types of giggers: free agents who derive their primary income from independent work and prefer it that way, casual earners who gig in order to supplement their income, also by choice, reluctants whose primary income comes from gigs but would prefer a traditional job, and the financially strapped who gig for supplemental income, but would prefer not having to [9]. Analysing the results, the McKinsey report concludes that, although the majority of giggers engage in such activities on their own volition, with 70-75\% of earners 
falling in the category of free agents or casual earners, the sheer number of 50 million Americans and Europeans who engage in gig work to make ends meet is a problem that's even more striking if we consider the 20 million of people whose primary income comes exactly from that kind of temporary and insecure employment [9].

In the next sections of the article, we will focus on analysing the birth and rise of gig work, its benefits, and drawbacks, as well as try to describe it.

\section{ITS ECONOMIC ORIGINS}

In order to understand how this new economic model came to be, one must go as back as the birth of the firm and the first and second industrial revolutions because, as Manyika et al. put it, "the future of independent work looks a lot like its past" [9; p.23].

Although some authors see gig economy's main selling point in its high levels of work flexibility, autonomy, and "work/life balance", in which enterprising individuals can use their skills and technological innovations to supplement their incomes [1], not everyone sees it as such an employee-oriented model. In fact, Friedman [4] argues that it is employers, not workers, who are actually pushing for it, as it is them who are able to control markets, modes of production, and employment in order to minimize costs and maximize profit, like they've been doing since the vast majority of the workforce shifted from self-employment to employment during the second industrial revolution.

As it often goes, economics' main concern is profit, and one of the surest ways to boost profit is lowering production costs which, as Zheng and Yang [2] put it, citing authors like Coase, Smith and Marx, was made possible firstly through the establishment of firms in the industrial era. Seen mainly as an economic approach in reducing the cost of recurring activities, such as transaction and production costs, firms were seen as a simple way to "internalize a large number of external transaction contracts, thereby greatly reducing transaction costs and realizing the uniform allocation and sale of all their resources and products." [2; p.3].

Following Coase's explanation of the birth of firms, Zheng and Yang [2] explain the rise of gig economy via a transformative combination of both the development of science and technology, as well as new insights in the fields of economics and social sciences, concerning human resources, management, and contemporary customers' needs.

While Coase's importance of firms in the era of industrialization was based on (1) an understanding of labour force being homogeneous, rational, economic, and in the pursuit of maximization of individual economic benefits, where (2) employers were free to segment production chains as market demand was homogeneous and massive, which (3) lead to an increase of the complexity of labour division, with workers being ever more low-skilled, and (4) where employers did not have readily available information about relative prices in order to set their own, Zheng and Yang [2] argue that a lot has changed since then.

Workers are no longer considered rational drones but are seen as "complex individuals with social, psychological, and democratic needs" [2; pp.4-5] who, in order to successfully cater a diversified market in which customers and consumers are demanding ever more personalized products and services, need to actively work on their skills, picking up more, and more diverse knowledge, every day. Firms, in their theory, are no longer the pinnacle of human economics, nor are they inevitable in order to successfully conquer the market as both the rise of information technology, and the micro-segmentation of markets lead to a reduction in production and transaction costs (thanks to the former), and to a need to deliver personalized products, which makes large-scale production much less useful (thanks to the latter). 
Following Zheng's and Yang's [2] approach, in this new economic model, where niches are norm, and technology permeates every part of entrepreneurship, gig economy has risen as a sensible response. Roy-Mukherjee and Harrison [11] summarize this "demand side" advantage of gig economy as a model that's able to provide goods and services at a lower price, while maintaining a greater variety of said goods and services, and deliver them faster and more customized compared to the traditional economy.

Even though such an explanation is surely plausible in terms of a lean management perspective, where firms ever so often seek to trim their non-essential personnel, or a "just-intime" perspective, where firms try to reduce their non-productive inventory to a minimum, restocking everything they need, as they need it; it is questionable how much this gig economy benefits giggers, and how much it benefits their non-existent employers.

\section{ITS SOCIAL CONSEQUENCES}

Although it only recently came to the attention of both academic and journalistic research, gig economy, in its "offline" version, along with other forms of non-standard employment, has been around for more than a few decades. As Muntaner [12] puts it, it has been more than four decades of shifts in labour markets in which contracts with unlimited duration, 40-hours per week, including benefits, have seen a steady decline as a "standard" form of employment.

There are two complementary explanations to this shift from standard to non-standard mode of employment with the foremost being a relative loss of workers' bargaining leverage due to the economic crisis of 2008 as put forward by Friedman, and Vallas and Schor [4, 13] and the second being a proliferation of information technology, enabling employers to make the most of their current advantage, as documented by statistics in app production [14, 15], as well as interviews with platform CEO-s [5, 16] (De Stefano - Biewald, Arcidiacono).

In the past 13 years, since both the iOS app store and the Google Play store opened for business, the number of apps available to download has risen dramatically, with the iOS app store counting almost 4,5 million apps in 2020 [14], and its counterpart almost 3 million [15]. Such a meteoric rise in the app markets opened a lot of doors for both giggers and users of gig services. As Arcidiacono et al. put it, quoting Robin Chase, "everything that can become a platform, will become a platform" [16; p.276]. With work platformizing ever more under the "participatory ethos of Internet culture" [16; p.276], the authors see gig economy as the newest economic paradigm.

Even though such a platformization of work is undeniably giving more flexibility to both workers and employers, Friedman [4] argues that the gig economy only sees its rise when workers lose their bargaining power with employers. Comparing the recent rise of the number of giggers to the decline of gig economy during the second Clinton administration and the employment boom caused by the internet, Friedman [4] sees the expansion of gig economy as a response to the global recession of 2008, in which labour market's forces of supply and demand were particularly skewed in favour of employers as lots of people lost their jobs, and were consequently flooding the market looking for another one. Such a view on the emergence of gig economy is shared by Vallas and Schor [13] who see the expansion of companies like Uber and Airbnb right after the Great Recession by making use of a "ready pool of workers" and question whether these platforms can be profitable or retain employees when labour markets are tight.

Building on his theory, Friedman [4] notes that long-term contracts, ever less present in contemporary employment, were a strategy companies used to "protect" themselves from employee shortages during times of high employment, as well as protecting their investments in human capital, and stabilizing wages which benefit employers in times of high employment and employees in times of low employment. Such practices are seen as 
unnecessary expenses during times of low employment. Arguing that not a lot of healthy, well, trained and responsible workers would accept precarious positions such as gigs, Friedman finds that, in order to hire "labour on the spot, they [corporations] need a reserve army of the unemployed available to work at stable wages." [4; p.180].

Combining a labour market of low employment, linked to a rise in app and platform technology, various businesses have found it economically logical to shift, at least in some part, from standard to non-standard employment, especially crowd work and on demand work, in order to boost their profits at the expenses of employees which are seen as pricey investments in times of high unemployment. As Friedman puts it, by "making employment and wages more flexible, gig employments shift the risk of economic fluctuations onto the worker" [4; p.172], which is mostly made possible by the economic strand this reserve army is dealing with, being willing to train, get educated or specialize at their own expenses, or being willing to work tasks to make ends meet.

That change has been recognized both by academics, with De Stefano arguing that "gig economy technologies provide access to an extremely scalable workforce" [5; p.476], and by the private sector controlling firms who provide platforms giggers use to find work. Two curious, almost villain worthy, examples of CEOs talking about their approach to workers can be found in De Stefano's [5] work, quoting the founder of CrowdFlower, Lukas Biewald, and the CEO of Amazon, Jeff Bezos. While Biewald is somewhat exalted by this incredible opportunity to find workers, "pay them the tiny amount of money, and then get rid of them when you do not need them anymore" [5; p.476], as such a type of employment would not have been possible before the internet, Bezos shows a much uglier face of gig work, referring to its practices as giving access to "humans as a service" [5; p.477].

Although such practices are criticised by authors [5,6] as commodifying either humans, where workers are found as nothing more than expendable resources, or labour, as institutional changes that shift the risks of market competition on workers instead of employers, not everyone shares these grim perceptions of the gig economy. In fact, Vallas and Schor, in their work [13] show four competing approaches to platform work, adding their own, and analysing their key positions, as it will be presented in the following chapter.

\section{FORMS OF PLATFORMS}

Depending on schools of thought, gig economy can be viewed as a positive, negative or neutral (in terms of being nothing more than a symptom of much larger and longer existing changes in the labour market) phenomenon.

Having said that, it is highly discouraging when authors, writing about the positive aspects of gig economy end the chapter comparing entrepreneurs to a "herd that, like livestock, can be milked or sheared to extract revenue." [13; p.277]. In their review of platforms as "Incubators of Entrepreneurialism" Vallas and Schor showcase the advantages platforms offer compared to a traditional economy. Quoting numerous authors, they reach the conclusion that platforms help reduce transaction costs, enable various segment of people to participate in gig work (i.e. residents from rural areas, people with disabilities or stay-at-home caregivers), as well as unlock the possibility for people to monetize their assets like cars, homes, tools or knowledge, which is also supported by research done by Churchil and Lyn [1]. Another kind of advantage in gig work is found in the trust building between customers and providers, enabled by the scoring system put in place by platforms in order to better understand, or control the quality of service provided and the needs of their (but not actually their) customers. Somewhat criticizing authors who argue that the shift in employment relations, due to platforms, is leading to a "networked society of microentrepreneurs" and that giggers 
are afforded a level of flexibility out of reach to those working 9-5 jobs, Vallas and Schor argue that it is "unlikely that platforms will foster crowd-based capitalism or lead power and control to assume horizontal, peer-based configurations." [13; p.278], as it is much more likely that platforms, thanks to network effects, will scale, monopolize, and dominate markets.

Moving from that "optimistic" view of gig economy, Vallas and Schor [13] explore the literature pertaining to grimmer aspects in which workers have to actively try to find ways to unionize informally, gaming the algorithms controlling them, and form social bonds of support with people they never met and, most likely, will never meet. Calling this segment "The Digital Cage" the authors describe a school of thought united in criticizing corporate human management, outcomes in evaluations and ranking systems, and the undermining of transparency, comparing platforms to a private version of the social credit systems, analogous to the one active in China. Platforms are, in this sense, seen as a barrier that effectively discourages and weakens workers' ability to challenge corporate rules by controlling available data, being constantly gathered but rarely fully shared with workers. Apart from that information control, platforms are seen as gamifying work by offering symbolic rewards in order to boost attachment to the app or platform, and implementing a modern day "divide et impera" approach by individualizing and dispersing workers which are rarely in contact with each other and consequently can not unionize or even gather to discuss their problems, and strengthening competition between them, as tasks are not always plentiful.

Vallas and Schor [13] argue that, although algorithms are definitely being used to corporate advantage, and that unionizing over social media leads to questionable achievements, such a view of the gig economy is overestimating and reifying the power of digital technology, adding examples of various tactics workers deploy in playing, defeating and even avoiding algorithms and company rules, more often than not, using the same technology that's used against them.

A third approach is found in exploring gig economy as an "Accelerant of Precarity" in which the digitalization and platformization of work is merely a drop in the bucket of work arrangements flexibilization that's been underway for decades; in other words, it is not the technology that's the problem, but the underlying societal and economic imbalances of power which leave workers in precarious positions. Coming back to the position of power of corporations, authors in this approach find firms externalizing risks at the expense of workers, much like Friedman and De Stefano $[4,5]$ would argue. Building on the "divide et impera" principle mentioned in the previous approach, this one's key feature can be found in the commodification of labour time, and disembeddedness of the worker from systems of social protection which is provided by platforms for firms to use in an attempt to limit their obligations to the workforce. Vallas and Schor [13], citing Harvey, argue that this approach is just another way of capital "accumulation through dispossession" in which businesses find legal and financial mechanisms to cut workers' rights. Agreeing with authors of this approach insofar that platforms are successfully avoiding the risks and costs of doing business by externalizing them to giggers, including "responsibility for bodily injury, damage to tools and assets, coverage between paid gigs, financial malfeasance by customers, and harassment" [13; p.280], Vallas and Schor [13] argue that analysing the gig workforce in this way is overly simplistic. Not every gigger uses platforms as the only source of income, and not every gigger ends up working low-paying tasks, consequently, depending on their dependency status, which they explain as how reliant on platform income giggers are, gig economy "could" decrease the precarity caused by other forms of employment. Although this approach very much seems like fighting fire with fire, statistics in the European Union and U.S.A. seem to support this conclusion with $58 \%$ and $54 \%$ independent workers respectively doing gigs as a way to supplement their income with $32 \%$ and $28 \%$ respectively doing it out of necessity in 2016 [9] 
The fourth approach present in literature finds platforms to be "Institutional Chameleons", in other words, the (be it positive or negative) effects of platforms vary depending on the macroinstitutional surroundings they operate in. As an example, Vallas and Schor [13] quote research on Uber done in various countries, and the effects it had as a disruptive technology, with the U.S.A. faring far worse than some European countries because it was seen as a threat to employment status (as it's linked to social insurance), whereas countries as Germany and Sweden had somewhat less problematic after-effects, linked to systems of urban-transportation (prominent in Germany) and the amount of tax revenue for the welfare state (prominent in Sweden). Authors representing this approach argue that the same technology that's being used to provide gigs and tasks could very easily be used to provide giggers with protection and work regulations, or, as Vallas and Schor put it, "given adequate institutional guidance, platforms could provide mechanisms for worker voice and social inclusion" [13; p.281]. Criticizing this approach, Vallas and Schor [13] note that platforms are not that malleable, and that they actually have a notable dose of power with which they, in fact, can shape institutional environments, especially in a globalizing world, pointing to a growing literature exploring differences between gig workers throughout the world and finding few or none.

Having found inconsistencies in each of the analysed approaches, Vallas and Schor [13] opt in giving one of their own. Calling it "Permissive Potentates" they "argue that platforms constitute a new type of governance mechanism with which employers can conduct economic transactions" [13; p.282] differing from hierarchies, markets or networks, in so far they do not centralize power like the first, nor do they disperse it like the seconds, or parcel it out to collaborators like the third. Platforms, in their opinion "exercise power over economic transactions by delegating control among the participants" [13; p.282], retaining authority over functions like allocation of tasks, data collection, pricing and revenue collection. In this form of power, platforms manage to remain powerful, even though, and perhaps because of ceding control over specific aspects of the labour process in order to externalize risks, while maintaining a position of "permissive predators" and letting giggers gig before exerting their power to exploit and profit.

Expanding on the notion of permissive power, Vallas and Schor [13] define four distinctive features of platforms pertaining to (1) their business model, (2) their transformation of employment, (3) supervision, and (4) spatial organization of work.

Concerning their business model, the authors note that platforms bring a novelty in the form of profiting from mediations done between workers and customers while completely avoiding the messiness of fixed costs and capital or direct employment. Their model depends on externalizing conventional costs but comes also in the added value of data mining. According to the authors, the astonishing growth of such firms rests also on their non-existent infrastructure, as they are not bounded by mortar and pestle, but can keep expanding without investing heavily in material structures. The second novelty is seen in the transformation of employment where platforms, unlike conventional firms, have little to no interest in control over work methods and schedules, as well as personnel selection criteria, to the point they not only allow giggers to work for how much and whenever they want, in most cases they even allow them to work for competing platforms as well. That kind of flexibility (as corroborated by Zheng and Yang [2]) is the most prominent selling point of platforms and it's been well researched by numerous authors mentioning both sides of the coin - workers who are thrilled by being their own boss $[1,5,7,17,18]$, as well as those who think this kind of freedom is a mirage $[1,4,5]$. That selling point will be further discussed in the next section of this article. The third novelty platforms introduced was a fictitious laissez-faire management with little to no supervision. Vallas and Schor [13] explain that, although platforms do not employ hierarchical controls and do not have a hands-on management like classic firms, leaving giggers with little to no scripting in terms of how to manage their time and tasks, they do 
have mechanisms of control in terms of algorithms and surveillance technology. That kind of control is also mentioned in the work of Glavin et al. [19] who explain that platform control is indirect, through monitoring and surveillance, with freelancing platforms monitoring screens and keystrokes of workers, or rideshare companies collecting data on driving, behaviour and transactions, as well as customer evaluations of giggers, which is both an important control mechanism as well as yet another expense platforms do not have to deal with - regular employee evaluations. The fourth and final feature Vallas and Schor [13] identify is the spatial (re)organization of work. Noting how, "ironically, the sharing economy leaves workers with reduced opportunities for a shared experience at work" the authors argue how, unlike firms in the industrial era, digital platforms need to disperse labour in order to be able to provide just-in-time service. The authors connect this spatial dispersion to two different phenomena, the first being that it fosters competitiveness and inequality between workers, and the second that it suppresses the ability for collective action among giggers.

Concluding their evaluation of platforms, Vallas and Schor [13] remain uncertain about the resilience of platforms over time, wondering whether they will be able to exert more control over giggers if need be, and how that would affect potential users, as well as their accountability in case classifications of giggers as employees becomes something laws from different countries decide to implement legally. On the other hand, if even more firms decide to abandon standard employment practices, platforms could very well further erode that kind of employment, having an even greater army of the unemployed at disposal. Finally, while refusing to speculate on the possible outcomes of platforms as an economic model of capital accumulation, the authors enumerate four possible futures - one with platforms consolidating in superplatforms, with an ever increasing monopoly, surveillance ability and corporate rule, a second with states successfully regulating them and balancing the interests of workers, users and owners, a third where platforms and social media will become intertwined, destabilizing the former and empowering both users and giggers, and a fourth, where platforms will be owned by their users as cooperatives, competing with capitalist firms.

Finally, we turn to examining the good sides and bad sides of gig work with a small caveat regarding these two adjectives: as both of them often carry different meanings depending on the recipient, this article will take the point of view of gig workers, rather than that of platforms or customers.

\section{BENEFITS AND BENEFICIARIES}

Starting from the most obvious one, generating revenue, gig economy can surely be seen as a star, in BCG matrix terms, by platforms and firms since it enables them to make full use of lean management and just-in-time economics, be it regarding tools, be it regarding people. On the other side giggers are not always faring better than their 9-5 counterparts. Although, as Friedman notes, "free to market their labour broadly, some middle-aged and well-educated independent contractors have high earnings...on average...most gig workers earn less than their equally educated counterparts on traditional contracts..." [4; p.178], not all gig workers are blessed with high incomes and steady cash flow. After all, the McKinsey report [9] notes low-income households are more likely to participate in independent work, with almost every second household with earnings amounting to less than 25000 \$ doing so, and $37 \%$ of them doing it out of necessity. Compared to high-income earners, that's a significant difference as only every third household with earnings over 75000 \$ engages in gig work, and less than $25 \%$ of them doing so out of need. Additionally, and although not directly linked to income, profiting from gig work does not come cheap, as independent workers often need to pay for their means of production (houses to rent, cars to drive people in, education to attain higher-paying gigs etc.), contribute to their own pensions and health insurance, and are unable to take paid 
sick leave or holidays. As Wood et al. note in their interview results, only "a handful of workers...could afford health insurance, but the vast majority were without any access to healthcare." [6; p.943] which, although is not a crucial problem in countries with regulated and subsidized healthcare, could definitely be a problem in countries with less prosocial regulations. Time spent searching, applying, and waiting for tasks also goes unpaid, as well as breaks, training or learning new skills to compete with workers globally, summarize Wood et al. [6].

Overall, gig work, at least in its currently unregulated state, seems to be benefiting different actors in different proportions, with platforms scooping the cream of the crop, highly educated and established independent contractors faring fairly well, as long as they have a stable list of clientele, while low-skilled or low-educated workers having to grind hours in order to make a stable profit, and where "income stability remains a mirage" [5; p.480] for the majority.

Another well-known selling point of gig economy is the ability to "be your own boss!", again, benefiting different actors in different ways. Being one's own boss is roughly equated to potential flexibility in work but, as De Stefano astutely notes, "this flexibility on the workers' side is often assumed to equate the undisputable flexibility the gig economy generally affords to businesses." [5; p.479]. It should not come as a surprise that a model made by business benefits business most, but why would a model that allows freedom of temporal and spatial flexibility be bad for gig workers? After all, Bessa and Tomlinson note how "a range of studies show that employees are more motivated, perform better and even work harder when they have some control over their working time, location of work or schedule." [20; p.157].

Explaining spatial flexibility, Zheng and Yang [2] note, it could be seen as a win-win condition for both workers and employers, where the former can choose their own workplace, improving efficiency and satisfaction, while the latter save on operating costs by not needing to rent working space. Although it could be argued that workers, in some cases, benefit from that spatial flexibility, not having an office is not an advantage in all cases, especially for people who do not live alone, do not have the possibility to equip a home-office, or do not have the financial possibilities to pay for all day long usage of utilities, externalized by businesses.

On the other hand, temporal flexibility is seen as "undoubtedly the embodiment of laborers' control over the working process" [2; p.8], although they do allow the possibility of giggers overworking themselves in times of economic strains, compromising their health, safety, and output quality. Unfortunately, both flexibilities are criticized by some authors. De Stefano, for instance, argues that competition between workers, which is sometimes led on a global scale, "pushes compensations so down that people may be forced to work very long hours and give up a good deal of flexibility in order to make actual earnings." [5; p.479]. Such a viewpoint is shared by Friedman, who argues that, as employment and income become more variable, workers are forced to work extra hard when they do manage to find tasks in order to compensate for down-times [4].

$\mathrm{Wu}$ et al. [21] openly challenge this fictitious flexibility arguing that, at least in the specific case of Uber in China, workers are left with far less flexibility than thought, all due to labour control strategies implemented by the platform. Enumerating three systems of "soft" control, namely economic control, emotional labour, and consent making, $\mathrm{Wu}$ and co-authors [21] argue that "being one's own boss" is not always that simple. Explaining how platforms need to "actively manipulate drivers' online time in order to accommodate the relatively high ride demands that accrue during peak hours" [21; p.584], the authors note that bonuses function as a highly effective economic control method. By offering bonuses, and guaranteeing a certain amount of money if the drivers did not meet their quotas, Uber successfully regulated flexibility by making drivers abide to simple conditions like working a set amount of minutes during peak periods, having high (above 4,7) customer ratings, completing at least 10 trips in 
the previous week, and having a ride-completion (accepting requests and competing the ride) higher than $45 \%$. Quoting Wu et al. "such bonuses and subsidies constituted a major proportion of an Uber driver's daily income, and in order to win these various bonuses, a driver would voluntarily extend online time and increase the number of rides offered beyond their own personal preferences" [21; p.585], we can easily see how fragile temporal flexibility can be in some cases, especially if we take into account their finding that drivers (especially those whose primary income came from Uber) would adapt their work schedules in order to accommodate customers during peak hours. Apart from economic control, another managerial method was found in the need of doing emotional labour to satisfy the customer evaluation system. As Wu and co-authors [21] note, the evaluation system, present, but by no means unique to Uber, functioned as a way to achieve hierarchical control without instituting organizational hierarchies by ranking drivers based on their customers' satisfaction and disciplining them if and when needed. Such a point of view is shared by other authors like Glavin et al. [19] and De Stefano, who argues that "the technology-enabled possibility of receiving instant feedbacks and rates of workers' performance is pivotal in ensuring businesses both flexibility and control at the same time." [5; p.478]. Not only did this kind of surveillance serve to increase drivers' trustworthiness, the authors argue it manipulated drivers insofar it was linked to bonuses (with low scores meaning no bonuses, which is seen as an economic punishment), which were in turn linked to peak hour bonuses, but it also pushed drivers with low scores to take on more work in hope to raise their ratings as they were calculated based on the last 500 rides, again, eroding temporal flexibility. Finally, through the process of consent making, $\mathrm{Wu}$ and others [21] argue that Uber used flexibility as a method to manufacture consent to its managerial strategies enabling drivers to retain a feeling of entrepreneurs by owning their own means of production and, at least to some extent, manage their own schedules. This nominal flexibility, authors argue, was used in order to make drivers more complacent when encountering reductions in pay rates, and less willing or able to unionize.

Finally, flexibility, much like profit generation, seems to be attainable only in some cases. Businesses will likely gain an economic advantage from this flexibilization, but gig workers do not always follow suit. This seems to be the case especially for those whose main source of income comes from gigging and cannot, like in China's Uber example, take the liberty to refuse riding in peak times and for long hours just in order to make as many bonuses as possible. Being one's own boss and working flexibly, be it temporally or spatially, does not seem to deliver on its promises of better balancing work-life relations. Sometimes, on the contrary, as Bessa and Tomlinson argue, these types of flexible contracts can even be "a source of anxiety for working parents, as these contracts prevent them from being able to plan and manage their finances and 'fragmented' time" [20; p.159]. In the end, even the sense of independence that comes with such flexible work arrangements can be put into (perhaps not that paranoid) question if one awakens to the ability platforms have of "uninterrupted 24/7 real-time monitoring of workers, likely raising the mental stress produced by close monitoring", as Muntaner notes [12; p.599].

Finally, one last understated, and perhaps not enough researched aspect of gig work is one's mental resilience and social needs. Although Churchill and Lyn note how "gig workers are able to avoid some of the more challenging aspects of the modern work-place, such as schedules, supervision, and co-workers" [1; p.742, emphasis added], with the absence of supervision already being questioned, the absence of co-workers and social relations at work is something that should not be undervalued. Urzì Brancati et al. argue that the atomization of jobs into tasks and the subsequent shifting of jobs into gigs would have an impact "beyond work organizations, as jobs are not only contracts for the provision of labour services, but, in 
Durkheim's words, they are a crucial anchor of 'organic solidarity', a system of representation rooted in and reflective of concrete social groups." [7; p.4]. Trying to explore the social and psychological ramifications of mostly working alone, and not having stable coworkers, in the wake of many researchers considering "the workplace as a key setting for forging social connections and a sense of belonging" [19; p.9], the authors conducted research on Uber drivers based on powerlessness, and loneliness. Fully aware that isolation can be used to prevent collective actions and that it can lead to the erosion of social contact between workers and organizations, they found that, perhaps unsurprisingly, platform workers report indeed greater levels of powerlessness and loneliness compared to the "standard" working force. Although few in numbers, research like these should find their place in exploring the, sometimes unexpected, far reaching effects of "gigging alone" and its consequences on workers, their social capital and overall work-life satisfaction.

\section{CONCLUSION}

As the use of technology permeates social and work life at an increasing pace, giving us ever more possibilities and ways to conduct business and socialize, sometimes for the better, sometimes for the worse, sociological thought must find its place in analysing, questioning and, when necessary, criticizing novel modalities of work.

Although gig work, or platform work, or independent work or any other name it goes by, is not a new phenomenon, it did indeed gain traction in the previous decade with the rise of global and powerful platforms and corporations. As such, gig work provided a lot of inspiration for social scientists and researchers, spanning across the borders of law, economics, sociology, political sciences, psychology, as well as philosophy. While the problem of gig work research does not seem to be its lack of documentation (one could argue its problem being the exact opposite) gig work does seem to be a phenomenon that, a few decades from its origin, is yet to be defined coherently and, if needed, merged with other types of independent work in order to be better understood.

Unfortunately, defining gig work does not seem to be under the jurisdiction of social sciences but it finds itself in the hands of policy makers whom, numerous authors, urge to regulate its meaning, rights and obligations, not only in order to make it easier to research but in order to pull gig workers out of their limited financial security.

Although the scope of this article was to shed some light on the definitions of gig work and its evolution, as well as to question its benefits and its beneficiaries, this matter will, at least in part, remain unresolved yet again. As definitions of gig work vary with every author and every research adding or subtracting some details, its origin (and consequently its goal) seems to be less elusive. Finding it in a combination of economics and information technology gig work's mission is seen in lowering expenditures and boosting flexibility in the contemporary economy. Unfortunately, that kind of mission does come with a price, and with lack of regulations platforms currently enjoy, that price is easily externalized to workers. Said workers, although expecting (and sometimes being promised) flexibility in both space and time of work, a healthy work-life balance, the possibility of being their own boss while gaining constant and high profits are not always able to achieve all, if any of the promised benefits. And while it is true that some independent workers, under some very specific circumstances, do enjoy this kind of gig, the majority of benefits is still reserved for the platforms and their owners who, in the process of commodifying and automatizing work, are paying little to no attention to the possible consequences of a major platformization of the economy. 


\section{REFERENCES}

[1] Churchill, B. and Lyn, C.: Gender in the gig economy: Men and women using digital platforms to secure work in Australia.

Journal of Sociology 55(4), 741-761, 2019,

http://dx.doi.org/10.1177/1440783319894060,

[2] Zheng, Q. and Yang, W.: The Characteristics of The Gig Economy.

Cambridge Open Engage, 2020,

http://dx.doi.org/10.33774/coe-2020-ldcpg,

[3] Täuscher, K. and Laudien, S.M.: Understanding platform business models: A mixed methods study of marketplaces.

European Management Journal 36(3), 319-329, 2018,

http://dx.doi.org/10.1016/j.emj.2017.06.005,

[4] Friedman, G.: Workers without employers: Shadow corporations and the rise of the gig economy.

Review of Keynesian Economics 2(2), 171-188, 2014,

http://dx.doi.org/10.4337/roke.2014.02.03,

[5] De Stefano, V.: The Rise of the "just-in-time workforce": on-demand work, crowdwork, and labor protection in the "gig-economy".

Comparative Labor Law \& Policy Journal 37(3), 471-504, 2016,

http://dx.doi.org/10.1080/01442872.2016.1188913,

[6] Wood, A.J.; Graham, M.; Lehdonvirta, V. and Hjorth, I.: Networked but Commodified: The (Dis)Embeddedness of Digital Labour in the Gig Economy.

Sociology 53(5), 931-950, 2019,

http://dx.doi.org/10.1177/0038038519828906,

[7] Urzì Brancati, M.C.; Pesole, A. and Férnandéz-Macías, E.: New evidence on platform workers in Europe.

Results from the second COLLEEM survey, EUR 29958 EN, Publications Office of the European Union, Luxembourg, 2020,

[8] Abraham, K.G.; Haltiwanger, J.C.; Sandusky, K. and Spletzer, J.R.: Measuring the Gig Economy: Current Knowledge and Open Issues.

AEA Papers and Proceedings 109, 357-361, 2019, http://dx.doi.org/10.1257/pandp.20191039,

[9] Manyika, J. et al.: Independent work: choice, necessity, and the gig economy.

McKinsey Global Institute, San Francisco, 2016,

[10] Gallup: Put the Gig Economy to Work for You.

Gallup, Washington, 2018,

[11] Roy-Mukherjee, S. and Harrison, M.: The Shifting Boundaries of Capitalism and the Conflict of Surplus Value Appropriation within the Gig Economy.

In: Page-Tickell, R. and Yerby, E. eds.: Conflict and Shifting Boundaries in the Gig Economy: An Interdisciplinary Analysis.

Emerald Publishing, Bingley, pp.45-62, 2020,

[12] Muntaner, C.: Digital Platforms, Gig Economy, Precarious Employment, and the Invisible Hand of Social Class.

International Journal of Health Services 48(4), 597-600, 2018, http://dx.doi.org/10.1177/0020731418801413,

[13] Vallas, S. and Schor, J.B.: What Do Platforms Do? Understanding the Gig Economy. Annual Review of Sociology 46, 273-294, 2020, http://dx.doi.org/10.1146/annurev-soc-121919-054857,

[14] Statista: Number of available apps in the Apple App Store from 2008 to 2020. https://www.statista.com/statistics/268251/number-of-apps-in-the-itunes-app-store-since-2008, accessed $6^{\text {th }}$ March 2021, 
[15] Statista: Number of available applications in the Google Play Store from December 2009 to December 2020.

https://www.statista.com/statistics/266210/number-of-available-applications-in-the-google-playstore, accessed $6^{\text {th }}$ March 2021,

[16] Arcidiacono, D.; Gandini, A. and Pais, I.: Sharing what? The 'sharing economy' in the sociological debate.

The Sociological Review Monographs 66(2), 275-288, 2018, http://dx.doi.org/10.1177/0038026118758529,

[17] Abraham, et al.: Measuring the Gig Economy: Current Knowledge and Open Issue. Social Science Research Network (w24950), 1-52, 2018,

[18] Findlay, P. and Thompson, P.: Contemporary work: Its meanings and demands. Journal of Industrial Relations 59(2), 1-117, 2017, http://dx.doi.org/10.1177/0022185616672251,

[19] Glavin, P.; Bierman, A. and Schieman, S.: Über-Alienated: Powerless and Alone in the Gig Economy.

The Canadian Quality of Work and Economic Life Study (C-QWELS) Project,

[20] Bessa, I. and Tomlinson, J.: Established, accelerated and emergent themes in flexible work research.

Journal of Industrial Relations 59(2), 153-169, 2017, http://dx.doi.org/10.1177/0022185616671541,

[21] Wu, Q.; Zhang, H.; Li, Z. and Liu, K.: Labor control in the gig economy: Evidence from Uber in China.

Journal of Industrial Relations 61(4), 574-596, 2019, http://dx.doi.org/10.1177/0022185619854472. 